\title{
The Effects of Pre-task and On-line Task Planning on L2 Learners' Oral Performance Level: An Empirical Study
}

\author{
Xiangyuan Feng ${ }^{1,}$ a
}

${ }^{1}$ Cazenove international tianjin yao hua middle school

aFengxiangyuan65@126.com

Keywords: Effects of pre-task; On-line task planning

\begin{abstract}
This paper aims at analyzing and discussing the combined effects of pre-task and on-line task planning on L2 learners' oral production through a movie review. In the first part, it will provide a literature review which represents the identified planning types and reviews the existing task-based research in different planning conditions. Then it will introduce the research gap, research questions, methods, findings and in the end pedagogical implications and limitations of the research.
\end{abstract}

\section{Introduction}

During the past decade, there has been a considerable amount of research investigating the impact of task design features and their implementing procedures on various aspects of L2 language performance, such as its complexity, accuracy and fluency (Skehan, 1996). Unfortunately, the inconsistency of results brought by a number of identified variables makes it difficult to accurately and precisely predict specific task performance. In comparison, planning as a key concerned implementation variable has been demonstrated to produce a relatively consistent and controlled impact (Ellis, 2005). Therefore, several studies have been conducted to investigate the effects of pre-task planning and on-line planning, which aims at predicting and controlling the outcomes of such kind of pedagogical tasks.

Inspired by the concept that language acquisition can be seen as information processing, planning plays a significant role in manipulating the cognitive theories into practice in the means of pedagogical tasks. According to Pica (1997), task-based research could be considered as efficient arenas in the field of SLA to build and develop the connection among theory, research and its pedagogical implementation. Therefore, as an EFL teacher and research, I intend to further examine the effects of planning time on learners' language development on the basis of the previous theories and research.

\section{Literature Review}

Planning Types. Seen as a problem-solving and decision-making activity, planning is applied, either automatically or intentionally, to select the appropriate linguistic devices in order to achieve effective message conveyance. It is recursive and proceeds at multiple levels (i.e. discourse, sentence, and constituent) throughout the whole information processing and language performance (Clark and Clark, 1977).

There are a number of different ways to distinguish types of planning in tasks, among which the most primary classification is the pre-task planning/on-line task planning binary. It is defined in terms of the time when planning is happening, either before or during the task is performed. 


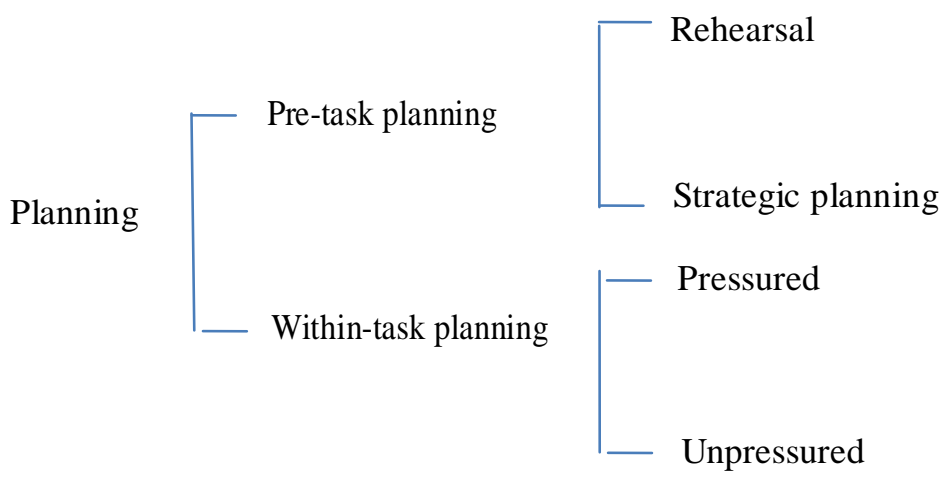

Figure 1. Types of task-based planning (Ellis, 2005: 4)

From Fig. 1 we could see that there are sub-categories in each of them. Pre-task planning can be further divided into rehearsal and strategic planning. Unlike other pre-task activities like content brainstorming or checking dictionary, rehearsal and strategic planning could access to the actual material of the task. Targeting exactly the content of a pedagogical task, learners are given opportunities to conceptualize and formulate their subsequent performance based on information retrieved from their first language (L1) and interlanguage (IL).

Studies conducted by Bygate $(1996,2001)$ and Gass et al. (1999) examined the effects of rehearsal on the subsequent performance of the same as well as different tasks. The results suggested that although rehearsal enhances complexity and fluency of the second performance of a same task (i.e. the "main" performance), it does not transfer effects to a new, similar task. Bygate (1999) believed that this type of "repetition" provides learners with extra processing space so as to direct their attention from message content (i.e. meaning) to formulation and monitoring of linguistic devices (i.e. form). In this way, learners can fulfill the completing demands of all aspects of language use. Similarly, studies on strategic planning (Yuan and Ellis, 1993; Foster, 1996; Skehan and Foster, 1997; Wendell, 1997; Ortega, 1999) found definite evidence of fluency enhancement, which are clearer in relatively difficult and cognition-demanding tasks such as narrative and decision making. Comparing to fluency, results from the previous research were failed to demonstrate clear effects of strategic planning on accuracy. While studies of Ellis (1987) and Mehnert (1998) found an increase of accuracy in specific language use, Wendell (1997), Yuan and Ellis (2003) failed to explore any evidence of that. Thus, an assumption can be made that the beneficial impact of strategic planning differs in terms of specific structures, task types and task conditions, which needs to be examined further. On-line task planning, which is much simpler than the former type, can be further distributed into two categories, that is whether or not learners are given extra time to planning during performance. According to Ochs (1979), when performers feel unpressured, they attend to more careful planning, resulting in relatively "planned language use". On the contrary, pressured performance leads to rapid and rough planning which generates the socalled "unplanned language use". From her investigation, positive results are demonstrated that unpressured planning could make the discourse more target-like and complex. Besides, instead of spending time on conceptualization and formulation in pre-task period, while-task planning provides learners with more opportunities to monitor their own production, and thus results in greater accuracy. However, according to Hulstjin and Hulstjin (1984)'s account, the effects on accuracy can only be found evident if the on-line planning proceeds with the focus-on-form.

In terms of both theory and pedagogy, it is of importance to carry out an empirical study on this issue. Which types or combination of varied types of planning can impact positively on L2 learners' task performance need to be examined carefully and systematically, through different context and reliable measurements 


\section{Research Questions}

1. Are fluency, accuracy and complexity of oral speech affected in the course of task performance without extra planning time?

2. Are fluency, accuracy and complexity of oral speech affected in the course of task performance with extra pre-task and on-line task planning time?

3. In which task condition is the variance of performance level more moderate, regarding fluency, accuracy and complexity?

\section{Method}

Participant. Participants taking part in this study were two Chinese full-time postgraduate students who study business at Lancaster University, UK. Both of them were 23 years old. By the time the data was gathered, they have been learning English as a second language for 10 years and living in UK for 7 months. Before coming to UK, they had no experience of being abroad or opportunities to communicate in English outside the classroom. The language proficiency of both participants were considered upper-intermediate level according to their IELTS test score (speaking score: 6.5, total score: 6.5). Taking their learning history and English proficiency into consideration, they can be seen as typical representatives of the Chinese postgraduate students studying abroad.

Procedure. The study involves only one aspect of language learning (i.e. speaking) in two specific task conditions (i.e. non-planning time compared to pre-task planning combined with careful on-line task planning time). The task required participants to produce an oral movie review after watching a comedic movie trailer with few lines, which was cognitively-demanding. The trailer was in their L1 (i.e. Chinese). It was about a group of girls whose only thing in common is their beautiful voice and love for music.

Task Condition One

Instructions of the task were also explained in Chinese, for better understanding. No extra planning time was provided to Participant A. She was required to perform the task immediately after watching the trailer and Chinese description. And her performance of the task had to be completed in limited time (10 minutes). Since the time length here was relatively longer for oral practices than other task-based research and thus may weaken the design of "no-extra planning time", participant A was asked to produce at least 2 points to support her arguments on each aspects (i.e. characters, plots, visual effects, sound effects or music, costume design, directing). And every point should be expressed in at least three sentences. As a result, she almost had no time for pre-task planning and was pushed to pressured performance.

Task Condition Two

In contrast, participant B was enabled to do the task with the assistance of both types of planning. During the pre-task planning, she was allowed to consider silently the subsequent speech in unlimited time, and meanwhile make notes. The participant was not allowed to use the notes during her actual performance. In the course of her planning, some textual guidance was provided on what and how she could make use of the time, which could be seen in Appendix 1.

Data Analysis Measures. The analysis of second language production needs a principle and standard way for dividing the written or spoken data into reliable units. In order to apply the allocation methods to a wide range of language data elicited from varied contexts, agreements have been established on the definition, criteria and categories of language units or "lexical chunks", such as C-unit (Loban, 1966), T-unit (Hunt, 1965; 1966; 1970) and AS-unit (Foster, Tonkyn and Wigglesworth, 2000). However, in terms of spoken language analysis, AS-unit is more suitable for its elliptical nature. Unlike $\mathrm{T}$-unit and $\mathrm{C}$-unit, which become inadequate facing such speech dysfluencies as incomplete sentences, hesitation and repetitions, AS-unit has been modified to analyse beyond a single clause, and thus "establishing a speaker's level of proficiency and evaluating the complexity of a particular performance by the speaker" (Foster, Tonkyn and Wigglesworth, 2000:365). 
Table 1. Measures of fluency, accuracy and complexity

\begin{tabular}{|c|c|c|c|}
\hline Complexity & $\begin{array}{c}\text { Ratio of clauses } \\
\text { to AS-units }\end{array}$ & $\begin{array}{c}\text { Mean Segmental } \\
\text { Type/Token Ratio } \\
\text { (MSTTR) }\end{array}$ & $\begin{array}{c}\text { Total number of } \\
\text { different } \\
\text { grammatical verb } \\
\text { forms }\end{array}$ \\
\hline Accuracy & $\begin{array}{c}\text { Ratio of error-free AS-units } \\
\text { to total number of AS-units }\end{array}$ & $\begin{array}{c}\text { Number of errors per 100 } \\
\text { words }\end{array}$ \\
\hline Fluency & \multicolumn{2}{|c|}{$\begin{array}{c}\text { Ratio of AS-units with self- } \\
\text { correction, repetition and } \\
\text { self-correction to total } \\
\text { number of AS-units }\end{array}$} \\
\hline
\end{tabular}

Data Coding. Once the data was coded by the researcher, another expert did the coding for the second time to ensure its reliability. The inter-coder reliability correlations were above .97 for the coding of the fluency and accuracy measures. However, the inter-coder reliability for complexity measures was relatively lower, between $92 \%$ and $96 \%$. As a result, two coders re-tested the results of complexity measures until the inter-coder reliability coefficients of 0.97 were achieved.

\section{Results (500)}

The results are coded and summarized in the case of three dimensions of task performance, which are illustrated in the following figures. However, it is worth mentioning that, although participant B was given unlimited time for on-line planning, she only used 9 more minutes for extra planning. Besides, in terms of the notes, participant B wrote only 100 words during the task, which is much less than the pre-task note with 813 words.

Table 2. Results for fluency measures

\begin{tabular}{|c|c|c|c|}
\hline Participant & Task time & $\begin{array}{c}\text { Number of } \\
\text { syllables per } \\
\text { minute }\end{array}$ & $\begin{array}{c}\text { Ratio of AS-units with self- } \\
\text { correction, repetition and self- } \\
\text { correction to total number of AS- } \\
\text { units }\end{array}$ \\
\hline A & First 5 minutes & 102 & 0.310 \\
\hline B & Last 5 minutes & 95 & 0.530 \\
\hline & First 5 minutes & 72 & 0.470 \\
\hline & Last 5 minutes & 62.4 & 0.692 \\
\hline
\end{tabular}

Accuracy. As Table 2 shows, difference of accuracy according to the performance phase is evident in terms of both measurements. The ratio of error-free clauses to total AS-units reduces while the number of errors per 100 words increases. In comparison, the difference between two time slices in condition one is less overt than condition two, in terms of both measures of accuracy. 
Table 3. Results for Accuracy Measures

\begin{tabular}{|c|c|c|c|}
\hline Participant & Task time & $\begin{array}{c}\text { Ratio of error-free } \\
\text { clauses to total number } \\
\text { of AS-units }\end{array}$ & $\begin{array}{c}\text { Number of errors per } \\
100 \text { words }\end{array}$ \\
\hline A & First 5 minutes & 0.620 & 2.300 \\
\hline B & Last 5 minutes & 0.455 & 2.730 \\
\hline & First 5 minutes & 0.764 & 1.968 \\
\hline & Last 5 minutes & 0.615 & 2.325 \\
\hline
\end{tabular}

Complexity. Compared to fluency and accuracy, the results of complexity are more complex and mixed. In terms of both syntactic variety and lexical variety, a slight decrease is indicated through statistics, concerning both task conditions. However, the patterns of ratio of clauses to AS-unit are different while comparing two conditions. As performances proceeding, unlike the decreasing tendency in all other changes of complexity, the ratio of clauses to AS-unit increases when there is ample time for pre-task and on-line task planning.

The results found in measures of complexity accuracy and fluency demonstrate that the provision of ample planning time, both pre-task and while-task, had impact on all three dimensions of participant B's oral discourse. Compared the results between two conditions accordingly, beneficial effects of planning time can be found in terms of accuracy and complexity, at the expense of fluency, which accords with the findings of some previous research (Ellis, 1987; Yuan and Ellis, 2003). Thus, it could be concluded that the combination of pre-task and unpressured on-line task planning facilitates both the accuracy and the complexity of L2 learners' oral performance but inhibits fluency. As a result, this finding provides a basis for the researcher to further answer the research questions of this study.

\section{Research and Pedagogical Implications}

This study has further investigated the award possibilities raised by Skehan and Foster (2005): 1) whether learners may have difficulty sustaining a high level of task performance over extended time; 2) whether the previous findings based on short piece of oral production may not be reliably generalized to the whole speech. In this case, the present study brings out some useful ideas into both pedagogy and research.

In terms of research, more should be taken into consideration while analyzing the speech data. The length of time learners complete a task, and the length of a task production being analyzed should be connected to the variance of accuracy, fluency and complexity. Besides, researchers should also carefully select or modify the most reliable and appropriate measures according to different contexts of research. Due to the multifaceted nature of different performance dimensions, more than one measure should be employed for each dimension to generate more reliable and generalizable results.

\section{Limitations}

Three limitations of this research need to be acknowledged. First, due to the time constraint, design of the current research makes it impossible to compare the oral task performance of a group of participants in all four conditions (i.e. four combinations consisting of two planning time). For example, if four different conditions are all examined and compared in the study, it may make more contributions for EFL teachers to allocating and using planning time in different pedagogical tasks.. Second, the spoken discourse being compared is produced by two different subjects. Although they share the similar learning history and context, individual differences are inevitable in the case of reasoning and linguistic patterns. It may affect the results when the cardinal number of participants is relatively small. However, given that they were identified to be equivalent in general language 
proficiency as well as speaking proficiency, this can be regarded as a minor problem. In comparison, the third limitation is more serious.

\section{References}

[1] Bygate, M. (1996). Effects of task repetition: Appraising the developing language of learners. In J. Willis and D. Willis (Eds.) Challenge and Change in Language Teaching (136-146). Oxford: Heinemann.

[2] Bygate,M. (1999). Task as the context for the framing, re-framing and unframing of language.System 27: 33-48.

[3] Bygate, M. (2001). Effects of task repetition on the structure and control of oral language. In M. Bygate, P. Skehan and M. Swain (eds), Researching Pedagogic Tasks, Second Language Learning, Teaching and Testing. Harlow: Longman.

[4]Clark, H., and Clark, G. (1977). Psychology and Language: An introduction to psycholinguistics. New York NY: Harcourt, Brace, Jovanovich.

[5] Ellis R. (1987). Interlanguage variability in narrative discourse: Style shifting in the use of the past tense. Studies in Second Language Acquisition 9: 1-20.

[6] Ellis, R. (2003). Task-based Language Teaching and Learning. Oxford: Oxford University Press.

[7] Ellis, R. (2005). Planning and task-based performance: Theory and research. Planning and task performance in a second language, 11, 4-33.

[8] Ellis, R., and Yuan, F. (2004). The effects of planning on fluency, complexity and accuracy in second language narrative writing. Studies in Second Language Acquisition 26: 59-84.

[9] Ellis, R., and Yuan, F. (2005). The effects of careful within-task planning on oral and written task performance. Planning and task performance in a second language, 167-192.

[10] Foster, P. (1996). Doing the task better: How planning time influences students' performance. In J. Willis and D. Willis (eds), Challenge and Change in Language Teaching. London: Heinemann.

[11] Foster P., and Skehan, P. (1996). The influence of planning on performance in task-based learning. Studies in Second Language Acquisition 18(3): 299- 324.

[12] Foster, P., and Skehan, P. (1999). The influence of source of planning and focus of planning on task-based performance. Language Teaching Research 3: 215-247.

[13] Foster, P., Tonkyn, A., and Wigglesworth, G. (2000).Measuring spoken language: A unit for all reasons. Applied Linguistics 21: 365.

[14] Gass, S., Mackey, A., Fernandez, M., and Alvarez-Torres, M. (1999). The effects of task repetition on linguistic output. Language Learning 49: 549-580.

[15] Housen, A., and Kuiken, F. (2009). Complexity, accuracy, and fluency in second language acquisition. Applied Linguistics, 30(4), 461-473.

[16] Hulstijn, J., and Hulstijn, H. (1984). Grammatical errors as a function of processing constraints and explicit knowledge. Language Learning 34: 23-43.

[17] Koponen, M., and Riggenbach, H. (2000). Overview: Varying perspectives on fluency. In H. Riggenbach (ed.), Perspectives on Fluency. Ann Arbor MI: The University of Michigan Press.

[18] Mehnert U. (1998). The effects of different lengths of time for planning on second language performance. Studies in Second Language Acquisition 20: 52-83.

[19] Ochs, E. (1979). Planned and unplanned discourse. In T. Givon (ed.), Syntax and Semantics Vol 12: Discourse and semantics. New York NT: Academic Press.

[20] Ortega, L. (1999). Planning and focus on form in L2 oral performance. Studies in Second Language Acquisition 21: 109-148. 